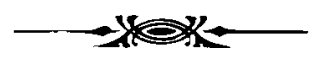

\title{
Aesop (6th Century bCe)
}

\section{Fables}

Source: Mythologia ethica, or, Three centuries of Aesopian fables (London: Printed for Thomas Hawkins, 1689), 251-52.

Herodotus identifies Aesop as a slave on the Greek island of Samos in the sixth century BCE. Plutarch identifies him as a fabulist at the court of Croesus in Lydia. Some traditions hold him to have been an African and indeed suggest that his name, "Aisopos," is the ancient Greek word for "The Ethiop." Aesop's fable of the Moor or Aethiopian appears in various forms in Bibles (Jeremiah 13), sermons (Dove), and emblem books (Palmer, Whitney) throughout the early modern period, becoming an emblem for both wasted labor and the fixity of color and identity.

Keywords: Washing the Ethiope-Moors-Blackness-Fixity of Color

Fable 34. The Moor or Aethiopian.

Strangely was a man mistaken, who having bought an Aethiopian, or Blacka-moor, imagined that that swarthy colour came by the fellow's slothfulness, in neglecting to keep himself clean; and with great labour and industry would fain have washed him white, but it was impossible; for all the many changes of water, and all the pains taken in rubbing and scrubbing him, could not make the Aethiopian change his hue.

This shows the impossibility of changing that which nature has fixed in man; and exposes their folly, who would attempt things which are impossible to be done. 